Article

\title{
Photo-Induced Charge Separation vs. Degradation of a BODIPY-Based Photosensitizer Assessed by TDDFT and RASPT2
}

\author{
Karl Michael Ziems@, Stefanie Gräfe and Stephan Kupfer *(D) \\ Institute of Physical Chemistry and Abbe Center of Photonics, Friedrich Schiller University Jena, \\ Helmholtzweg 4, 07743 Jena, Germany; karl-michael.ziems@gmx.de (K.M.Z.); s.graefe@uni-jena.de (S.G.) \\ * Correspondence: stephan.kupfer@uni-jena.de; Tel.: +49-3641-948334
}

Received: 21 September 2018; Accepted: 1 November 2018; Published: 5 November 2018

\begin{abstract}
A meso-mesityl-2,6-iodine substituted boron dipyrromethene (BODIPY) dye is investigated using a suite of computational methods addressing its functionality as photosensitizer, i.e., in the scope of light-driven hydrogen evolution in a two-component approach. Earlier reports on the performance of the present iodinated BODIPY dye proposed a significantly improved catalytic turn-over compared to its unsubstituted parent compound based on the population of long-lived charge-separated triplet states, accessible due to an enhanced spin-orbit coupling (SOC) introduced by the iodine atoms. The present quantum chemical study aims at elucidating the mechanisms of both the higher catalytic performance and the degradation pathways. Time-dependent density functional theory (TDDFT) and multi-state restricted active space perturbation theory through second-order (MS-RASPT2) simulations allowed identifying excited-state channels correlated to iodine dissociation. No evidence for an improved catalytic activity via enhanced SOCs among the low-lying states could be determined. However, the computational analysis reveals that the activation of the dye proceeds via pathways of the (prior chemically) singly-reduced species, featuring a pronounced stabilization of charge-separated species, while low barriers for carbon-iodine bond breaking determine the photostability of the BODIPY dye.
\end{abstract}

Keywords: BODIPY; photocatalysis; multiconfigurational calculations; TDDFT

\section{Introduction}

The supply of renewable and sustainable energy sources is among the key scientific and technological endeavors of the 21st century [1-5]. Essentially promising is hereby the conversion of solar radiation, which could provide approximately $3 \times 10^{24} \mathrm{~J}$ of usable energy per year, thus exceeding human kinds current energy demands by several orders of magnitude [5], i.e., by virtue of solar cells, as well as by solar energy conversion to produce chemical fuels from carbon dioxide or water [5-7].

In the field of solar fuels, a plethora of devices based on semiconductors [8-12] and photoactive dyes in homogeneous as well as in multi-component systems [13-17] were thoroughly studied to promote hydrogen generation. The initial absorption of (sun)light and the supply of photoelectrons by the photosensitizer (PS) is essential for any further application in solar energy conversion. Therefore, the absorption spectrum of a PS should feature a pronounced overlap with the solar radiation spectrum, spanning from the near infrared to the UV region to enable efficient light-harvesting. Furthermore, long-term (photo- and thermal) stability, suitable electrochemical properties to enable (inter- or intramolecular) electron transfer and long excited-state lifetimes, in combination with low production costs and toxicity, are highly desired [18]. Since the 1970s, mostly transition metal complexes based on ruthenium, platinum, iridium, and rhenium, were employed as PSs in photocatalysis [3,18-27]. 
However, such complexes are commonly high priced and toxic, which limits their wide-range application. An alternative are low-cost earth-abundant metal-free PSs containing organic dyes, such as fluorescein, porphyrins, or eosin Y [15,16,28-33]. Moreover, boron dipyrromethene (BODIPY) (IUPAC name: 4,4-difluoro-4-bora-3a,4a-diaza-s-indacene) dyes were used as light-harvesting units in inter- [34] and intramolecular [35-39] photocatalytic hydrogen evolution.

BODIPY dyes combine broad absorption features from the visible to the UV range with high extinction coefficients, high quantum yields, and photostability, while these photophysical and photochemical properties can be easily tailored by structural modification $[40,41]$. Thus, a vast variety of BODIPY dyes have been reported and investigated with extensive experimental and theoretical efforts [40,42-49]. Several BODIPY dyes for application in two-component photocatalysis were prepared Beweries et al. and investigated by a suite of spectroscopic, e.g., UV-VIS and time-resolved spectroscopy, and computational methods [50,51]. This multicomponent approach utilizes a BODIPY PS (denoted 1), triethylamine (TEA) as a sacrificial electron donor, and $\left[\mathrm{Pd}\left(\mathrm{PPh}_{3}\right) \mathrm{Cl}_{2}\right]_{2}$ as a precursor for catalytically-active palladium nanoparticles in tetrahydrofuran (THF)/water (see Scheme 1a).

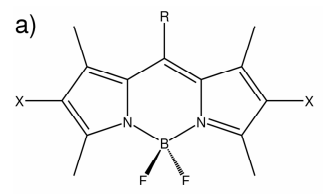

PS

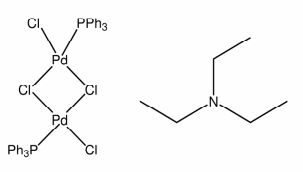

Pd source b)

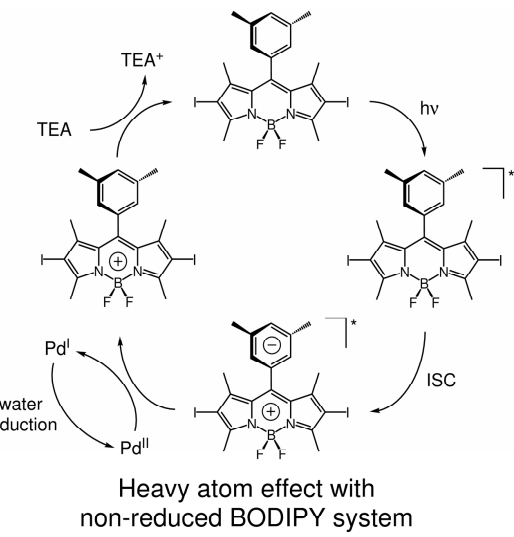

c)

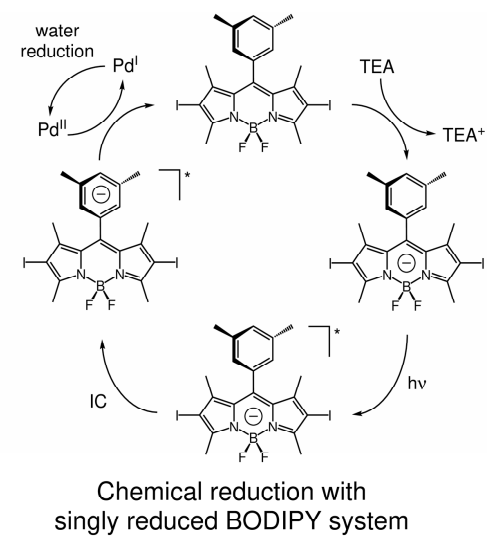

Scheme 1. (a) Two-component systems investigated by Beweries et al. consisting of a BODIPY PS, Pd source for water reduction, and TEA as a sacrificial electron donor [50,51]. Suggested catalytic cycles based on (b) the heavy atom effect via the non-reduced BODIPY system, and (c) the chemical reduction followed by photo-excitation of the singly reduced dye and internal conversion (IC).

Introduction of a mesityl group at the meso-position allowed enhancing the previously reported long-term stability of $20 \mathrm{~h}$ by a factor of ten. At the same time, the catalytic turn-over was increased by a factor of seven by virtue of iodine substituents at the positions 2 and 6 of the BODIPY $\left(X_{1}\right.$ and $\mathrm{X}_{2}$ ) compared to the unsubstituted parent compound $\left(\mathrm{X}_{1}=\mathrm{X}_{2}=\mathrm{H}\right)$ [50]. According to Beweries et al., the enhanced catalytic activity of the iodinated species, 1 , is ascribed to an efficient intersystem crossing (ISC) between the initially populated excited singlet states and the nearby long-lived charge-separated triplet states by virtue of sizeable spin-orbit coupling (SOC) introduced by the iodine atoms. In the following, a probable reduction of the charge-separated dye by the sacrificial electron donor (TEA) leads to the formation of a singly-reduced species with the excess charge stabilized on the terminal mesityl moiety. Subsequent intermolecular electron transfer among the PS and $\left[\mathrm{Pd}\left(\mathrm{PPh}_{3}\right) \mathrm{Cl}_{2}\right]_{2}$ generates the catalytically-active palladium species, which leads to the formation of molecular hydrogen. Experimental evidence for such a population transfer via ISC is given by the low emission quantum yields and low singlet excited-state lifetimes in comparison with the unsubstituted BODIPY dye, while the population of long-lived charge-separated states is suggested by transient absorption spectroscopy and time-dependent density functional theory (TDDFT) simulations [50]. This mechanism is denoted in the following as heavy atom mechanism. An alternative scheme-not relying on efficient ISC-is labelled a reductive mechanism in what follows, whereby the PS is initially reduced by TEA and subsequently photoexcited. The excitation of the reduced dye (with the excess charge on the BODIPY core) then leads to a charge transfer to the mesityl group and further-in 
accordance with the previously introduced heavy atom mechanism - to an intermolecular electron transfer to $\left[\mathrm{Pd}\left(\mathrm{PPh}_{3}\right) \mathrm{Cl}_{2}\right]_{2}$ and $\mathrm{H}_{2}$ evolution. The catalytic cycles for both schemes, the heavy atom, as well as the reductive mechanism, are illustrated in Scheme 1. However, under catalytic conditions, photodegradation, i.e., cleavage of the carbon-iodine bonds, occurs after approximately $20 \mathrm{~h}$ leading, in consequence, to the formation of the catalytically less active unsubstituted parent BODIPY $\left(\mathrm{X}_{1}=\mathrm{X}_{2}\right.$ $=\mathrm{H})[50]$.

The present fully computationally study aims at elucidating the coupled photo-induced redox processes, namely the heavy atom mechanism vs. the reductive mechanism (Scheme 1), associated with the generation of the reduced BODIPY dye enabling the catalytically active reduced palladium species, while SOCs are calculated to rationalize ISC processes. Furthermore, the quantum chemical simulations intend to determine the excited state relaxation channels associated to C-I bond cleavage and, thus, the photodegradation of the PS and the decrease of the catalytic activity. To this aim, and in contrast to the previous joint synthetic-spectroscopic-theoretical study, the excited state landscape of 1 is investigated in various oxidation and spin states using state-of-the-art multiconfigurational methods, i.e., multi-state restricted active space perturbation theory through second-order on a restricted active space self-consistent field reference (MS-RASPT2//RASSCF). The application of multiconfigurational methods for the present BODIPY dye is essentially mandatory since computationally less demanding TDDFT simulations are well known to yield contradictory results for this class of compounds [52-54].

This paper is organized as follows: Section 2.1 comprises the preliminary benchmark calculations at the RASPT2 and TDDFT level of theory applied subsequently to unravel the photo-induced reaction mechanism in Section 2.2 and the photodegradation channels in Section 2.3. Section 3 describes the quantum chemical methods and the methodology to assess the timescales of ISC processes. Finally, discussion and conclusions are provided in Section 4.

\section{Results and Discussion}

To assess the photophysics and the photochemistry of 1, its initial photo-excitation in the Franck Condon (FC) region is conscientiously investigated by TDDFT and RASPT2 simulations, while, subsequently, the relaxation mechanisms and degradation pathways are elucidated.

\subsection{Preliminary Benchmark}

As stated before, TDDFT lacks accuracy for describing multiconfigurational systems and boron-species in general [42,55-57]. Therefore, a preliminary benchmark was conducted, comparing the excited-state properties in the FC region at the TDDFT and the RASPT2 levels of theory within the equilibrium structures of the non-reduced singlet $\left(\mathrm{S}_{0}, \mathbf{1}^{\mathbf{0}}\right)$ and the singly-reduced doublet $\left(\mathrm{D}_{0}\right.$, $\left.{ }^{2} \mathbf{1}^{-1}\right) \mathrm{C}_{2 \mathrm{v}}$-restricted dye, see Table 1 and Figures $\mathrm{S} 1$ and S2. TDDFT slightly overestimates the bright HOMO-LUMO transition $\left(S_{1}\right.$ and $\left.D_{5}\right)$, localized on the BODIPY core by 0.17 and $0.20 \mathrm{eV}$ for ${ }^{\mathbf{1}} \mathbf{1}^{\mathbf{0}}$ and ${ }^{2} 1^{-1}$, respectively, in comparison to MS-RASPT2, which is related to the initial photo-activation. Contrarily, PBE0 substantially underestimates the dissociative and charge transfer (CT) states by up to $1.1 \mathrm{eV}$. The later CT states, where charge migration takes place from the BODIPY core to the phenyl moiety, are in general dark; therefore, a direct population of such states is highly unlikely. An exception is the CT state $\mathrm{D}_{5}$ of $\mathrm{A}_{2}$ symmetry as obtained by MS-RASPT2 for the singly-reduced doublet $\left({ }^{2} \mathbf{1}^{-1}\right)$, see Table 1. This state-or rather the excitation into this state-results in an oscillator strength of 0.15 a.u. Furthermore, a substantial deviation of the excitation energy of $1.4 \mathrm{eV}$ compared to the corresponding TDDFT state $\left(\mathrm{D}_{2}\right)$ is obtained. This discrepancy originates from the mixed electronic character in the multiconfigurational calculations. The contribution of the respective CT transition, $\pi_{4}{ }^{*}\left(b_{2}\right)$ to $\pi_{\mathrm{ph}, 4}{ }^{*}\left(a_{2}\right)$, is merely $29 \%$, while an intraligand transition (IL) of the BODIPY fragment, $\pi_{4}{ }^{*}\left(b_{2}\right)$ to $\pi_{4}{ }^{*}\left(\mathrm{a}_{2}\right)$, contributes with $38 \%$. Therefore, it is presumably that the increased oscillator strength-in comparison to PBE0-is a consequence of the (bright) IL contribution (see Table S6). A separation of these two transitions into separated electronic states could not be achieved, e.g., by alteration of the applied level shift and the RAS partitioning. 
Table 1. Comparison of TDDFT and RASPT2 $\left(\mathrm{RAS}_{\mathrm{Diss}}\right.$ and RAS $\mathrm{CT}_{\mathrm{C}}$ ) results, namely the excitation energies, oscillator strengths, and excited state characters obtained in the $\mathrm{C}_{2 \mathrm{v}}$-restricted GS structures ${ }^{1} \mathbf{1}^{0}$ and ${ }^{2} \mathbf{1}^{-1}$, respectively.

\begin{tabular}{|c|c|c|c|c|c|c|c|c|c|}
\hline \multicolumn{10}{|c|}{${ }^{1} 1^{0}$ (Non-Reduced Singlet Structure) } \\
\hline \multirow{2}{*}{\multicolumn{3}{|c|}{ Transition }} & \multicolumn{3}{|c|}{ TDDFT } & \multicolumn{4}{|c|}{ RASPT2 } \\
\hline & & & State & $E / \mathrm{eV}$ & $f$ & State & $E / \mathrm{eV}$ & $f$ & RAS \\
\hline$\pi_{3}\left(\mathrm{a}_{2}\right)$ & $\rightarrow$ & $\pi_{4}^{*}\left(\mathrm{~b}_{2}\right)(\mathrm{IL})$ & $\mathrm{S}_{1}\left(\mathrm{~B}_{1}\right)$ & 2.88 & 0.518 & $\mathrm{~S}_{1}\left(\mathrm{~B}_{1}\right)$ & 2.71 & 0.938 & Diss \\
\hline$\pi_{2}\left(\mathrm{a}_{2}\right)$ & $\rightarrow$ & $\pi_{4}^{*}\left(\mathrm{~b}_{2}\right)(\mathrm{IL})$ & $\mathrm{S}_{3}\left(\mathrm{~B}_{1}\right)$ & 3.45 & 0.311 & $\mathrm{~S}_{2}\left(\mathrm{~B}_{1}\right)$ & 3.65 & 0.094 & Diss \\
\hline$\pi_{3}\left(\mathrm{a}_{2}\right)$ & $\rightarrow$ & $\sigma^{*}\left(\mathrm{a}_{1}\right)$ (Diss) & $\mathrm{S}_{8}\left(\mathrm{~A}_{2}\right)$ & 4.41 & 0.000 & $\mathrm{~S}_{3}\left(\mathrm{~A}_{2}\right)$ & 5.06 & 0.000 & Diss \\
\hline$\pi_{3}\left(a_{2}\right)$ & $\rightarrow$ & $\sigma^{*}\left(b_{1}\right)$ (Diss) & $\mathrm{S}_{11}\left(\mathrm{~B}_{2}\right)$ & 4.55 & 0.000 & $\mathrm{~S}_{5}\left(\mathrm{~B}_{2}\right)$ & 5.42 & 0.001 & Diss \\
\hline$\pi_{3}\left(\mathrm{a}_{2}\right)$ & $\rightarrow$ & $\pi_{4}^{*}\left(\mathrm{~b}_{2}\right)(\mathrm{IL})$ & $\mathrm{T}_{1}\left(\mathrm{~B}_{1}\right)$ & 1.55 & - & $\mathrm{T}_{1}\left(\mathrm{~B}_{1}\right)$ & 1.88 & - & Diss \\
\hline$\pi_{2}\left(\mathrm{a}_{2}\right)$ & $\rightarrow$ & $\pi_{4}^{*}\left(\mathrm{~b}_{2}\right)(\mathrm{IL})$ & $\mathrm{T}_{2}\left(\mathrm{~B}_{1}\right)$ & 2.58 & - & $\mathrm{T}_{2}\left(\mathrm{~B}_{1}\right)$ & 3.04 & - & Diss \\
\hline$\pi_{\mathrm{ph}, 2}\left(\mathrm{~b}_{1}\right)$ & $\rightarrow$ & $\pi_{4}^{*}\left(\mathrm{~b}_{2}\right)(\mathrm{CT})$ & $\mathrm{T}_{6}\left(\mathrm{~A}_{2}\right)$ & 3.90 & - & $\mathrm{T}_{7}\left(\mathrm{~A}_{2}\right)$ & 4.93 & - & $\mathrm{CT}$ \\
\hline$\pi_{3}\left(\mathrm{a}_{2}\right)$ & $\rightarrow$ & $\sigma^{*}\left(\mathrm{a}_{1}\right)$ (Diss) & $\mathrm{T}_{7}\left(\mathrm{~A}_{2}\right)$ & 4.02 & - & $\mathrm{T}_{5}\left(\mathrm{~A}_{2}\right)$ & 4.83 & - & Diss \\
\hline$\pi_{3}\left(\mathrm{a}_{2}\right)$ & $\rightarrow$ & $\sigma^{*}\left(b_{1}\right)$ (Diss) & $\mathrm{T}_{8}\left(\mathrm{~B}_{2}\right)$ & 4.11 & - & $\mathrm{T}_{6}\left(\mathrm{~B}_{2}\right)$ & 5.09 & - & Diss \\
\hline$\pi_{\mathrm{ph}, 3}\left(\mathrm{a}_{2}\right)$ & $\rightarrow$ & $\pi_{4}^{*}\left(\mathrm{~b}_{2}\right)(\mathrm{CT})$ & $\mathrm{T}_{11}\left(\mathrm{~B}_{1}\right)$ & 4.29 & - & $\mathrm{T}_{8}\left(\mathrm{~B}_{1}\right)$ & 5.09 & - & $\mathrm{CT}$ \\
\hline$\pi_{3}\left(\mathrm{a}_{2}\right)$ & $\rightarrow$ & $\pi_{\mathrm{ph}, 5^{*}}\left(\mathrm{~b}_{1}\right)(\mathrm{CT})$ & $\mathrm{T}_{12}\left(\mathrm{~B}_{2}\right)$ & 4.39 & - & $\mathrm{T}_{10}\left(\mathrm{~B}_{2}\right)$ & 5.51 & - & $\mathrm{CT}$ \\
\hline$\pi_{3}\left(\mathrm{a}_{2}\right)$ & $\rightarrow$ & $\pi_{\mathrm{ph}, 4}^{*}\left(\mathrm{a}_{2}\right)(\mathrm{CT})$ & $\mathrm{T}_{13}\left(\mathrm{~A}_{1}\right)$ & 4.46 & - & $\mathrm{T}_{11}\left(\mathrm{~A}_{1}\right)$ & 5.52 & - & $\mathrm{CT}$ \\
\hline \multicolumn{10}{|c|}{${ }^{2} 1^{-1}$ (Singly Reduced Doublet Structure) } \\
\hline \multirow{2}{*}{\multicolumn{3}{|c|}{ Transition }} & \multicolumn{3}{|c|}{ TDDFT } & \multicolumn{4}{|c|}{ RASPT2 } \\
\hline & & & State & $E / \mathrm{eV}$ & $f$ & State & $E / \mathrm{eV}$ & $f$ & RAS \\
\hline$\pi_{4}^{*}\left(b_{2}\right)$ & $\rightarrow$ & $\pi_{\mathrm{ph}, 5^{*}}\left(\mathrm{~b}_{1}\right)(\mathrm{CT})$ & $\mathrm{D}_{1}\left(\mathrm{~B}_{1}\right)$ & 2.04 & 0.000 & $\mathrm{D}_{1}\left(\mathrm{~B}_{1}\right)$ & 2.11 & 0.000 & $\mathrm{CT}$ \\
\hline$\pi_{4}^{*}\left(b_{2}\right)$ & $\rightarrow$ & $\pi_{\mathrm{ph}, 4^{*}}^{*}\left(\mathrm{a}_{2}\right)(\mathrm{CT})$ & $\mathrm{D}_{2}\left(\mathrm{~A}_{2}\right)$ & 2.11 & 0.000 & $\mathrm{D}_{5}\left(\mathrm{~A}_{2}\right)$ & 3.54 & 0.150 & $\mathrm{CT}$ \\
\hline$\pi_{4}^{*}\left(b_{2}\right)$ & $\rightarrow$ & $\sigma^{*}\left(\mathrm{a}_{1}\right)$ (Diss) & $\mathrm{D}_{3}\left(\mathrm{~A}_{1}\right)$ & 2.12 & 0.000 & $\mathrm{D}_{1}\left(\mathrm{~A}_{1}\right)$ & 2.58 & 0.000 & Diss \\
\hline$\pi_{4}^{*}\left(b_{2}\right)$ & $\rightarrow$ & $\sigma^{*}\left(b_{1}\right)$ (Diss) & $\mathrm{D}_{4}\left(\mathrm{~B}_{1}\right)$ & 2.26 & 0.000 & $\mathrm{D}_{3}\left(\mathrm{~B}_{1}\right)$ & 2.83 & 0.000 & Diss \\
\hline$\pi_{3}\left(\mathrm{a}_{2}\right)$ & $\rightarrow$ & $\pi_{4}^{*}\left(\mathrm{~b}_{2}\right)(\mathrm{IL})$ & $\mathrm{D}_{5}\left(\mathrm{~A}_{2}\right)$ & 2.69 & 0.194 & $\mathrm{D}_{2}\left(\mathrm{~A}_{2}\right)$ & 2.49 & 0.183 & $\mathrm{CT}$ \\
\hline$\pi_{2}\left(\mathrm{a}_{2}\right)$ & $\rightarrow$ & $\pi_{4}^{*}\left(\mathrm{~b}_{2}\right)(\mathrm{IL})$ & $\mathrm{D}_{6}\left(\mathrm{~A}_{2}\right)$ & 3.38 & 0.003 & $\mathrm{D}_{4}\left(\mathrm{~A}_{2}\right)$ & 3.35 & 0.010 & $\mathrm{CT}$ \\
\hline$\pi_{3}\left(\mathrm{a}_{2}\right)$ & $\rightarrow$ & $\sigma^{*}\left(a_{1}\right)$ (Diss) & $\mathrm{Q}_{1}\left(\mathrm{~B}_{1}\right)$ & 3.55 & - & $\mathrm{Q}_{1}\left(\mathrm{~B}_{1}\right)$ & 4.26 & - & Diss \\
\hline$\pi_{3}\left(\mathrm{a}_{2}\right)$ & $\rightarrow$ & $\sigma^{*}\left(\mathrm{~b}_{1}\right)$ (Diss) & $\mathrm{Q}_{3}\left(\mathrm{~A}_{1}\right)$ & 3.64 & - & $\mathrm{Q}_{2}\left(\mathrm{~A}_{1}\right)$ & 4.43 & - & Diss \\
\hline$\pi_{3}\left(\mathrm{a}_{2}\right)$ & $\rightarrow$ & $\pi_{\mathrm{ph}, 5^{*}}\left(\mathrm{~b}_{1}\right)(\mathrm{CT})$ & - & - & - & $\mathrm{Q}_{3}\left(\mathrm{~A}_{1}\right)$ & 4.72 & - & $\mathrm{CT}$ \\
\hline
\end{tabular}

In accordance with the computational result for the doublet states of the reduced system the quartet states within ${ }^{2} \mathbf{1}^{-1}$, associated to C-I bond cleavage and CT, are likewise underestimated by approximately $0.8 \mathrm{eV}$ at the TDDFT level of theory. However, with excitation energies exceeding $4 \mathrm{eV}$ (MS-RASPT2), these quartet states are very unlikely to participate in the subsequent excited state relaxation cascades upon photoexcitation in the visible region.

Despite, the deviation of the PBE0 results from the RASPT2 reference values, TDDFT allows a qualitative evaluation of the low-lying excited states of the present BODIPY dye. However, the tendency of the applied TDDFT protocol to underestimate CT and dissociative states needs to be considered. For simplicity, the TDDFT notation is utilized to label the electronic states of interest in the following.

\subsection{Light-Induced Charging of the PS}

The following section aims at elucidating the photo-mechanism associated to the formation of the charge-separated BODIPY species after initial excitation into the low-lying bright IL state of ${ }^{\mathbf{1}} \mathbf{1}^{\mathbf{0}}\left(\mathrm{S}_{1}\right)$ and ${ }^{2} 1^{-1}\left(D_{5}\right)$ and subsequent relaxation along the excited state potential energy (hyper-)surface (PES).

\subsubsection{Heavy Atom Mechanism}

Within the framework of the suggested heavy atom mechanism-starting in the ${ }^{\mathbf{1}} \mathbf{1}^{\mathbf{0}}$ geometryexcitation into the bright $S_{1}$ state is followed by ultrafast ISC into long-lived and low-lying charge-separated triplet states. The probability of such population transfer from $S_{1}$ to the triplet 
manifold is determined by the respective SOCs obtained within the FC region of ${ }^{\mathbf{1}} \mathbf{1}^{\mathbf{0}}$ at the MS-RASPT2 level of theory. The multiconfigurational calculations reveal merely two triplet states, $\mathrm{T}_{1}$ and $\mathrm{T}_{2}$, at 1.88 and $3.04 \mathrm{eV}$, in the vicinity of the bright $\mathrm{S}_{1}$ state $(2.71 \mathrm{eV})$ within the $\mathrm{FC}$ region. The spin-orbit interaction $\left(\mathrm{C}_{2 \mathrm{v}}\right.$-restricited) of both triplet states $\left(\mathrm{B}_{1}\right)$, local excitations of the BODIPY fragment, and $\mathrm{S}_{1}$ $\left(\mathrm{B}_{1}\right)$ are forbidden by means of symmetry, see Table S7. Charge-separated triplet states from the BODIPY core to the phenyl moiety, $\mathrm{T}_{10}$ and $\mathrm{T}_{11}$, feature excitation energies of approximately $5.5 \mathrm{eV}$ and display very small SOCs of 0.0 and $0.5 \mathrm{~cm}^{-1}$ with $\mathrm{S}_{1}$, respectively. The highest coupling of $S_{1}$ is obtained with $\mathrm{T}_{7}(4.93 \mathrm{eV})$ with merely $5.3 \mathrm{~cm}^{-1}$. Pronounced SOCs are obtained among the singlet ground state and high lying dissociative triplet states, e.g., $\mathrm{T}_{5}$ at $4.83 \mathrm{eV}\left(778.0 \mathrm{~cm}^{-1}\right)$ and the higher order dissociative state $\mathrm{T}_{7}$ in the RAS $\mathrm{Riss}_{\text {Di }}$ a $5.83 \mathrm{eV}\left(925.5 \mathrm{~cm}^{-1}\right)$.

The computational results shown in Section 2.1 clearly reveal that the CT states of interests are high in energy and inaccessible from $\mathrm{S}_{1}$ within the FC region. However, upon structural relaxation, these states might undergo substantial stabilization. Thus, several excited singlet, $S_{1}, S_{2}, S_{3}, S_{8}$, and $S_{11}$, and triplet states, $T_{1}, T_{6}, T_{7}, T_{8}, T_{11}, T_{12}$, and $T_{13}$ were fully optimized using TDDFT. The respective singlet and triplet states were tracked within each equilibrium structure and displayed in a so-called geometry-states correlation diagram for ${ }^{\mathbf{1}} \mathbf{1}^{\mathbf{0}}$. As can be easily seen in Figure 1 , all CT states $\left(\mathrm{T}_{6}, \mathrm{~T}_{11}, \mathrm{~T}_{12}\right.$, and $\mathrm{T}_{13}$ ) undergo only slight stabilization to $3.57,3.89,4.07$, and $4.17 \mathrm{eV}$ upon relaxation, respectively. Thus, a population transfer from $\mathrm{S}_{1}$ to any $\mathrm{CT}$ state is energetically unfavorable.

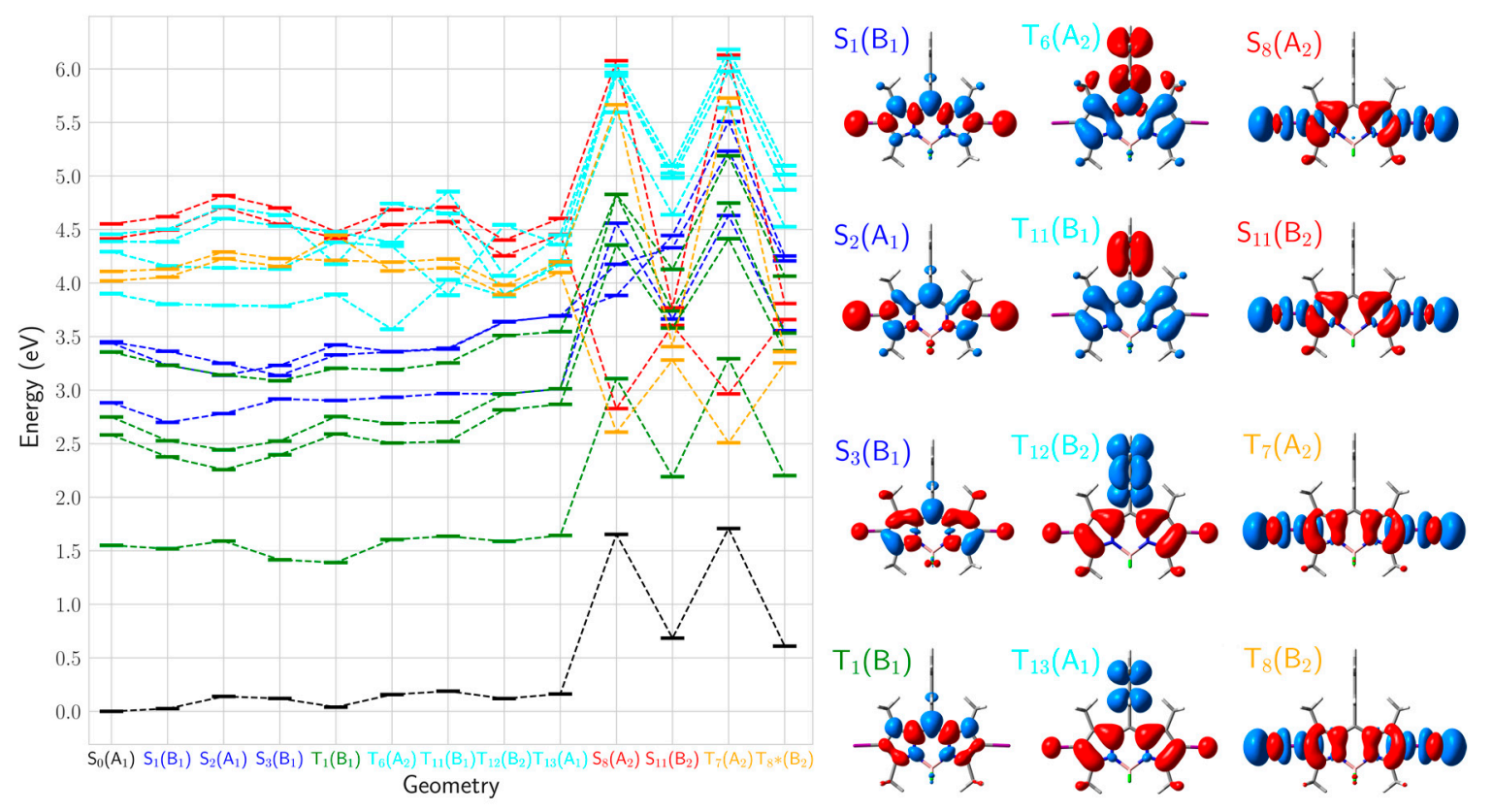

Figure 1. TDDFT geometry-states correlation diagram and charge density differences of the corresponding states. Asterisks indicate non-converged geometries, where the last step of the optimization procedure has been taken. Color code: singlet ground state (black), singlet state of IL character (blue), dissociative singlet state (red), triplet state of IL character (green), dissociative triplet state (orange), and triplet CT state (cyan).

A reason for the high lying CT states is the orthogonal alignment of the BODIPY core with respect to the phenyl moiety within the $\mathrm{C}_{2 \mathrm{v}}$-restricted partially optimized equilibrium structure and, thus, the omitted overlap of the $\pi$-systems. Therefore, a relaxed TDDFT scan along a dihedral connecting the main- and side-ring with a step size of $5^{\circ}$ was carried out. The calculated PESs are displayed in Figure 2a, which reveal a substantial stabilization of up to $0.98 \mathrm{eV}$ at $45^{\circ}$ for the $\mathrm{T}_{6} \mathrm{CT}$ state. The discontinuity of the $\mathrm{T}_{6}$ PES between 75 and $80^{\circ}$ is associated to a mixing of the HOMO with the iodine p-orbitals. As mentioned in Section 3, full relaxation leads to a reduction of the symmetry from $C_{2 v}$ to $C_{2}$, while the global singlet ground state is found with a slightly non-orthogonal $\left(\sim 85^{\circ}\right)$ 
alignment of the aromatic planes. The ground, as well as all investigated excited states, are stabilized from the $C_{2 v}\left(90^{\circ}\right)$ to the $C_{2}\left(85^{\circ}\right)$ equilibria merely by $0.1 \mathrm{eV}$. Thus, the reduction of the degrees of freedom to $C_{2 v}$ as utilized in the preliminary benchmark simulations presented in Section 2.1 is feasible. The vibrational modes corresponding to this torsion are found at low frequencies, i.e., $45 \mathrm{~cm}^{-1}$, $71 \mathrm{~cm}^{-1}, 102 \mathrm{~cm}^{-1}$, and $170 \mathrm{~cm}^{-1}$, see Figure S3. Considering a thermal energy of $0.026 \mathrm{eV}$ (room temperature), a displacement along the relaxed PES up to $69^{\circ}$ is feasible, which leads in consequence to a lowering of the $\mathrm{T}_{6} \mathrm{CT}$ state from $3.9\left(\right.$ at $90^{\circ}$ ) to $3.0 \mathrm{eV}\left(\right.$ at $\left.69^{\circ}\right)$. Thus, the energy gap between $S_{1}$ and $\mathrm{T}_{6}$ is substantially decreased. However, recalling the benchmark from Section 2.1, CT states are underestimated using PBE0 by $\sim 0.8 \mathrm{eV}$.

a)

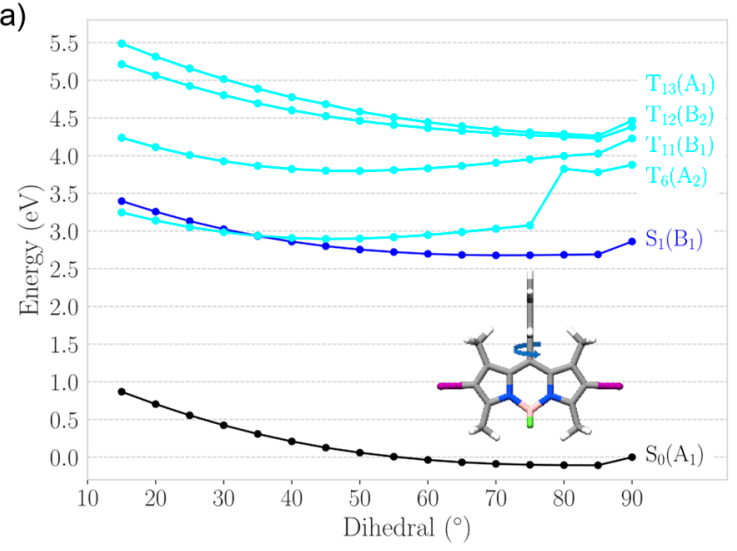

b)

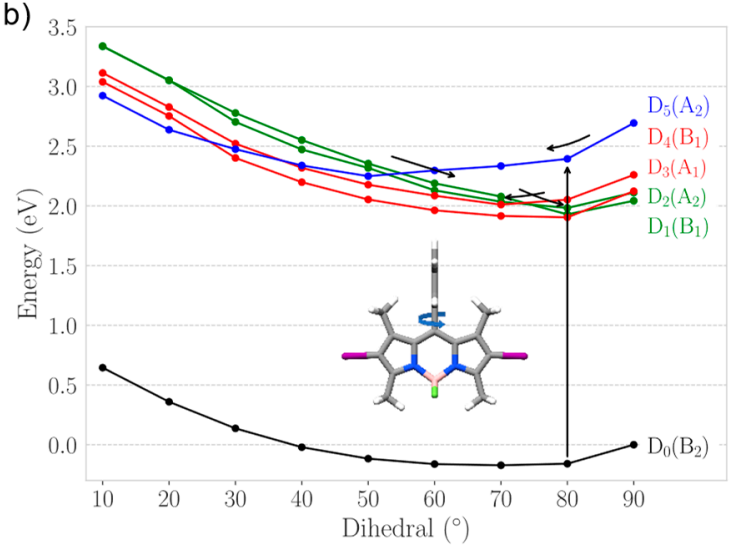

Figure 2. Relaxed TDDFT scan around a dihedral connecting the two aromatic ring systems for ${ }^{1} 1^{0}(a)$ and ${ }^{2} \mathbf{1}^{-1}(\mathbf{b})$. Arrows indicate a possible relaxation pathway starting from the bright $\mathrm{D}_{5}$ state in ${ }^{\mathbf{2}} \mathbf{1}^{-\mathbf{1}}$. Colour code: ground state (black), bright excited singlet/doublet state (blue), triplet CT states (cyan), dissociative doublet state (red), CT doublet state (green).

In order to re-evaluate the possibility of a population transfer from $\mathrm{S}_{1}$ to the triplet $\mathrm{CT}$ states, the SOCs were re-calculated at a distorted structure $\left(55^{\circ}\right)$ - at the vicinity of the crossing of $S_{1}$ and $\mathrm{T}_{6}$ as obtained by TDDFT. Analogous to the $\mathrm{C}_{2 \mathrm{v}}$-restricted structure, couplings of $0.1-4.0 \mathrm{~cm}^{-1}$ were obtained at the MS-RASPT2 level of theory (see Table S8). Thus, and albeit the pronounced stabilization of the charge-separated triplet states upon distortion, no evidence for a population transfer from the bight $S_{1}$ to the close-by triplet states is present.

\subsubsection{Chemical Reduction Mechanism}

The second proposed reaction mechanism addressing the generation of the catalytic active BODIPY species is based on a preliminary chemical reduction of the PS to form the singly-reduced BODIPY $\mathbf{2}^{\mathbf{2}}$, followed by photo-excitation into the low-lying $\mathrm{D}_{5}$ state and subsequent charge transfer processes within the excited states. In contrast to the non-reduced dye, ${ }^{\mathbf{2}} \mathbf{1}^{-\mathbf{1}}$ features two low-lying CT states, $\mathrm{D}_{1}$ and $\mathrm{D}_{2}$ at 2.04 and $2.11 \mathrm{eV}$, well below the bright $\mathrm{D}_{5}$ at $2.69 \mathrm{eV}$. Thus, population of these dark CT states upon photoexcitation of the bright $\pi \pi^{*}$ state $\left(\mathrm{D}_{5}\right)$ and subsequent relaxation and internal conversion is feasible. As discussed in Section 2.1, TD-PBE0 is in good agreement with MS-RASPT2 regarding the properties of the low-lying excited doublet states of the reduced dye, while the disagreement of MS-RASPT2 with respect to the TDDFT $\mathrm{D}_{2}$ state $(2.11 \mathrm{eV})$ originates from a pronounced mixing with a $\pi \pi^{*}$ transition in the multiconfigurational calculations.

Analogous to the investigation of the non-reduced system, a geometry-states correlation diagram is presented in Figure 3 comprising $\mathrm{D}_{0}-\mathrm{D}_{4}$. The diagram reveals a pronounced stabilization of the $\mathrm{CT}$ states upon equilibration below $2 \mathrm{eV}$, while the structural variations are rationalized by minor alterations of the bond lengths of the aromatic rings. This finding is in contrast to the results obtained for the non-reduced dye, where no pronounced stabilization of the CT states was observed. However, even more substantial stabilization is observed for the dissociative $D_{3}$ state, which is found in its 
optimized structure below the former doublet ground state and, thus, may lead to photodegradation (see Section 2.3).

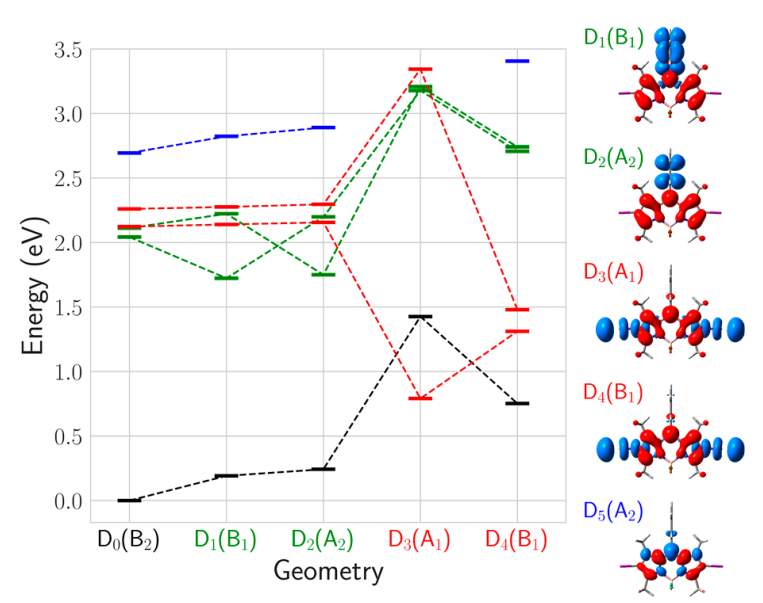

Figure 3. TDDFT geometry-states correlation diagram for the first five doublet states and charge density differences. Color code: doublet ground state (black), bright excited doublet state (blue), dissociative doublet state (red), and CT doublet state (green). Since $\mathrm{D}_{3}\left(\mathrm{~A}_{1}\right)$ becomes the electronic ground state within its equilibrium, the bright $\mathrm{D}_{5}$ state cannot be described in this structure using a single determinate method, i.e., TDDFT.

In addition, the potential energy landscape is studied along an internal coordinate describing the relaxed torsion of the boron fragment with respect to the phenyl moiety. This internal coordinate is closely related to the low-frequency vibrational modes at $39 \mathrm{~cm}^{-1}, 71 \mathrm{~cm}^{-1}, 97 \mathrm{~cm}^{-1}$, and $168 \mathrm{~cm}^{-1}$, (see Figure S4). As shown in Figure 2b), the diabatic potential energy curves of the initial populated $\mathrm{D}_{5}\left(\pi \pi^{*}\right.$ character) and the low-lying CT states cross between $50^{\circ}$ and $55^{\circ}$. A further crossing of $\mathrm{D}_{5}$ and the two dissociative doublet states $\left(D_{1}\right.$ and $\left.D_{2}\right)$ is accessible at approximately $30^{\circ}$ with an energy of $\sim 2.5 \mathrm{eV}$, considering an initial excitation energy of $2.69\left(\mathrm{C}_{2 \mathrm{v}}\right.$ structure $)$ or $2.55 \mathrm{eV}\left(\mathrm{C}_{2}\right.$ at $\left.80^{\circ}\right)$. Finally, the two charge-separated states $\left(D_{1}\right.$ and $\left.D_{2}\right)$ intersect with the two dissociative states $\left(D_{3}\right.$ and $\left.D_{4}\right)$ in the vicinity of the $\mathrm{FC}$ region of the fully-relaxed ground state $\left(\mathrm{C}_{2}\right.$ symmetry), where all four excited states $\left(D_{1}-D_{4}\right)$ are almost degenerate. Interestingly, structural distortion along this dihedral angle to the $\mathrm{C}_{2}$ minimum at $80^{\circ}$ stabilizes the doublet ground state, as well as all low-lying excited states by approximately $0.2 \mathrm{eV}$, while the oscillator strength of the $\mathrm{CT}$ states increases to approximately 0.012 . Thus, even a direct photo-induced population of these CT states is possible for the singly-reduced dye. The participation of (low-lying) quartet states in the excited state relaxation cascades is excluded since the lowest quartet states are found at $4.26 \mathrm{eV}$ at the MS-RASPT2 and at $3.55 \mathrm{eV}$ at the TDDFT levels of theory with ${ }^{2} \mathbf{1}^{-1}$ (Table 1). Therefore, no SOCs were calculated for the singly-reduced dye.

Finally, it is concluded that upon chemical reduction by a sacrificial electron donor (TEA), the desired photo-induced CT from the BODIPY fragment to the phenyl moiety competes with dissociative excited state relaxation channels leading to the photodegradation of the PS. The latter photodegradation processes, i.e., C-I bond breaking, will be elucidated in the following.

\subsection{Photodegradation}

Experimentally, the observed decline in catalytic performance of the present BODIPY PS after $\sim 20 \mathrm{~h}$ of irradiation is attributed to photo-degradation, namely to C-I bond breaking and the subsequent formation of the catalytically less active unsubstituted parent dye. The performed quantum chemical simulations aim at studying such dissociative processes at a molecular level.

As shown for the non-reduced as well as for the singly reduced dye, dissociative states of $\pi \sigma^{*}$ nature are located well above the bright $\pi \pi^{*}$ state in the FC region. However, these dissociative states undergo pronounced stabilization upon structural distortion and cross eventually with the initially 
populated $\pi \pi^{*}$ state. The light-driven C-I splitting is first investigated for the non-reduced dye $\left({ }^{\mathbf{1}} \mathbf{1}^{\mathbf{0}}\right)$ and subsequently for the singly reduced dye $\left({ }^{1} 1^{-1}\right)$.

In the FC region of the non-reduced dye, the dissociative states- $S_{8}$ and $S_{11}$-are found at excitation energies exceeding $4 \mathrm{eV}$, thus, a population transfer from the bright $\mathrm{S}_{1}$ (TDDFT: $2.88 \mathrm{eV}$ and MS-RASPT2: $2.69 \mathrm{eV}$ ) at this geometry is unfeasible (recall Table 1). In addition, population transfer from $S_{1}$ into the lowest dissociative triplet states- $\mathrm{T}_{7}$ and $\mathrm{T}_{8}$-is predicted to take place above $4 \mathrm{eV}$ in the $\mathrm{C}_{2 \mathrm{v}}$-restricted structure, while SOCs of merely $40 \mathrm{~cm}^{-1}$ are calculated between the respective states (Table S9). However, substantial stabilization of the dissociative singlet and triplet states is observed in the geometry-states correlation diagram (Figure 1) for the singly-dissociative states, $\mathrm{S}_{8}$ and $\mathrm{T}_{7}$, and for the doubly dissociative states, $\mathrm{S}_{11}$ and $\mathrm{T}_{8}$, upon relaxation. Dissociation was further investigated using relaxed PESs along the stretched C-I bonds. Vibrational modes or linear-interpolated (internal or Cartesian) coordinates were intentionally not utilized, since major distortion along such coordinates is necessary to stabilize the respective dissociative states sufficiently, which also leads to a sizable distortion of the aromatic system. Figure 4 a depicts the diabatic PESs of the bright $S_{1}$ state, as well as the dissociative singlet and triplet states along the singly-dissociative coordinate. Surprisingly, $\mathrm{S}_{8}$ and $\mathrm{T}_{7}$ undergo pronounced stabilization and cross the diabatic bright $\pi \pi^{*}$ state at 2.4 and $2.3 \AA$, respectively. However, no dissociative behavior is observed since both PESs feature a shallow minimum at $\sim 2.7 \AA$, while additional $0.8 \mathrm{eV}$ are required to reach the crossing with the singlet ground state at an excitation energy of $3.7 \mathrm{eV}$ and an elongation of $R=3.85 \AA$. Thus, the energy provided upon excitation into the bright $\mathrm{S}_{1}$ in the FC region (TDDFT: $2.88 \mathrm{eV}$ and MS-RASPT2: $2.69 \mathrm{eV}$ ) is insufficient to populate the dissociative states along the relaxed singly-dissociative coordinate. DFT simulations exceeding an elongation of $4 \AA$ failed to converge. In addition, the concerted cleavage of both carbon-iodine bonds was evaluated using TDDFT along a relaxed doubly-dissociative coordinate (Figure S5), as well as using the MS-RASPT2 along an unrelaxed doubly-dissociative coordinate of $C_{2 v}$ symmetry (Figure S6). The multiconfigurational calculations indicate once more to a slight overestimation of the $S_{1}$ state and an underestimation of the dissociative states by TDDFT along the reaction coordinate, while no complete dissociative behavior is observed.

a)

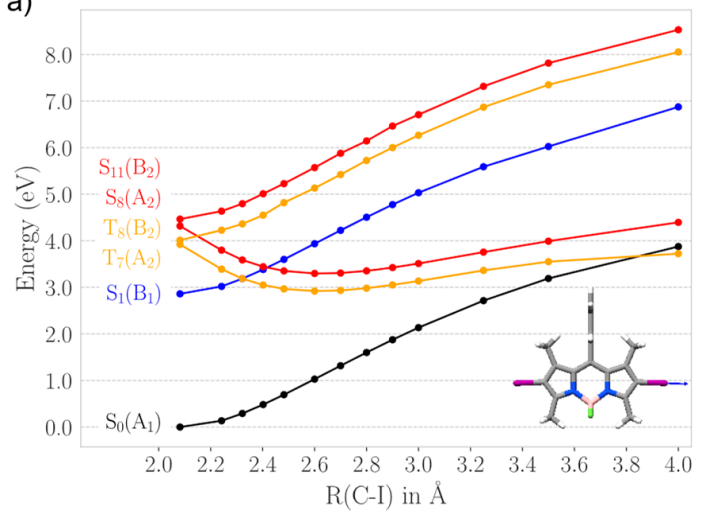

b)

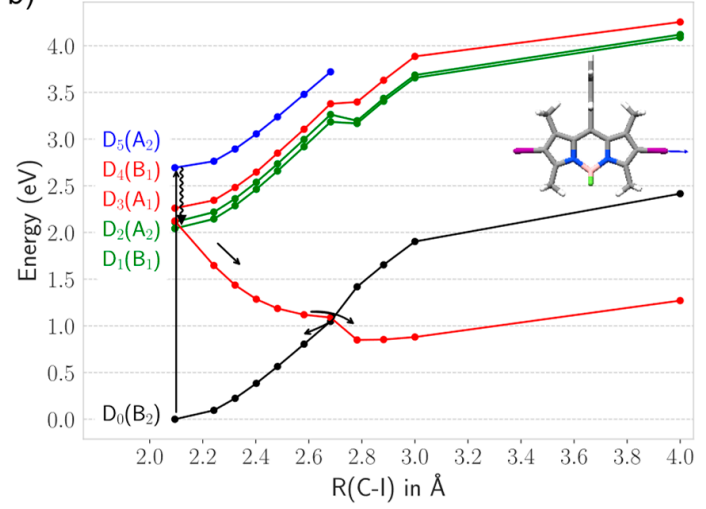

Figure 4. Relaxed TDDFT singly dissociative coordinate for the non-reduced (a) and reduced (b) dye. Arrows indicate a possible relaxation pathway starting from the bright $\mathrm{D}_{5}$ state via IC to the dissociative $\mathrm{D}_{3}$ state and further back to $\mathrm{D}_{0}$. Color code: ground state (black), bright excited singlet/doublet state (blue), dissociative singlet/doublet state (red), dissociative triplet state (orange), and CT doublet state (green).

Moreover, to populate the dissociative triplet states, $T_{7}$ and $T_{8}$, an ISC from the bright $S_{1}$ is essential. To quantify the kinetics of such process, the SOCs of the respective states were incorporated in the golden-rule expression for radiationless transitions, see Equation (1) [58]. For both cases-the population transfer from $S_{1}$ to $T_{7}$ and from $S_{1}$ to $T_{8}$-the calculated rate constants of $1.69 \times 10^{4}$ and $1.51 \times 10^{3} \mathrm{~s}^{-1}$, respectively, suggest rather slow processes (see Table S10). The calculated SOCs within 
the FC region between $S_{1}$ and $T_{7}$ as well as between $S_{1}$ and $T_{8}$ are with 0.6 and $39.2 \mathrm{~cm}^{-1}$ relatively small. Therefore, the SOCs were re-evaluated using MS-RASPT2 (with RAS Diss $_{\text {) }}$ ) in the vicinity of the $S_{1} / T_{7}$ and $S_{1} / T_{8}$ crossing regions; these structures were derived by fitted quadratic potentials (see Figure S8 and Table S11). However, the obtained couplings of $1.7\left(\mathrm{~S}_{1} / \mathrm{T}_{7}\right)$ and $53.0 \mathrm{~cm}^{-1}\left(\mathrm{~S}_{1} / \mathrm{T}_{8}\right)$ do not indicate a pronounced dependency of the SOCs along structural distortion within the studied range. Accordingly, similar values of $k_{\text {ISC }}$ are obtained within the estimated crossing regions.

The influence of structural distortion on the SOCs was further investigated for selected points along the unrelaxed doubly dissociative coordinate, see Figures S6 and S7 for more details, while in agreement with the previous results no pronounced deviations of the $S_{1} / T_{7}$ and $S_{1} / T_{8}$ couplings were determined. The quantum chemical calculations for ${ }^{\mathbf{1}} \mathbf{1}^{\mathbf{0}}$ addressing possible photodegradation pathways-associated to iodine dissociation-upon $S_{1}$ excitation reveal that the population of dissociative singlet states is energetically unfavorable. However, ISC towards the energetically less unfavorable dissociative triplet states may occur on longer time scales, which is in accordance with the experimentally-observed decline of catalytic activity upon approximately $20 \mathrm{~h}$.

In addition to the evaluation of the photostability of the present BODIPY-based PS within its non-reduced redox state, degradation channels upon single reduction by TEA were evaluated. The reduced dye, previously identified as the starting point for the light-induced charge separation, exhibits low-lying dissociative states, namely $\mathrm{D}_{3}$ and $\mathrm{D}_{4}$, within the GS equilibrium geometry $\mathbf{2}^{\mathbf{- 1}}$ (see Table 1). Therefore, excitation into the bright $\mathrm{D}_{5}$ state may lead in consequence to the population of degradative excited state relaxation channels, i.e., $\mathrm{D}_{3}$ and $\mathrm{D}_{4}$. The geometry-states correlation diagram depicted in Figure 3 visualized the substantial stabilization of $\sim 1.4 \mathrm{eV}$ for the equilibrated singly-dissociative state, $\mathrm{D}_{3}$. The doubly-dissociative state, $\mathrm{D}_{4}$, features no pronounced stabilization compared to $\mathrm{D}_{3}$ and was already classified as non-dissociative for ${ }^{\mathbf{1}} \mathbf{1}^{\mathbf{0}}$ and was consequently not considered in the following. Analogously to ${ }^{\mathbf{1}} \mathbf{1}^{\mathbf{0}}$, the potential energy landscape of the ground and low-lying excited states of ${ }^{2} \mathbf{1}^{-1}$ was examined using a relaxed singly-dissociative coordinate. As evident from Figure $4 b$, relaxation along the singly dissociative $D_{3}$ state is a prominent deactivation pathway from the bright $D_{5}$ state. At approximately $2.7 \AA$, the dissociative state crosses with the doublet ground state. At this point and beyond, the (TD)DFT results have to be handled with caution due to the pronounced multiconfigurational character of the electronic states. In the case of the reduced dye, the singly-dissociative state is a prominent relaxation channel that may be populated from the FC region, which leads to a barrier-free cleavage of a C-I bond and, thus, to photo-degradation. Moreover, the crossing with $\mathrm{D}_{0}$ provides an explanation for the experimentally-observed iodine formation after several hours of irradiation.

\section{Computational Details}

All DFT and TDDFT calculations in the present study were performed using the Gaussian 09 [59] program, while all multiconfigurational simulations were carried out in Molcas 8.0 [60]. In order to reduce the computational demand without affecting the photophysical properties, the mesityl group was replaced by a phenyl moiety.

The ground state equilibrium structures of the non-reduced singlet $\left(\mathrm{S}_{0},{ }^{1} \mathbf{1}^{\mathbf{0}}\right)$ and the singly-reduced doublet $\left(\mathrm{D}_{0},{ }^{2} \mathbf{1}^{-1}\right)$ of the investigated dye-both involved initially in the proposed catalytic cycles-were optimized by means of DFT. Additionally, DFT simulations were performed to study the equilibrium structure of the non-reduced triplet $\left(\mathrm{T}_{1},{ }^{3} \mathbf{1}^{\mathbf{0}}\right)$ species. The hybrid-functional PBE0 [61] and the correlation-consistent double- $\zeta$-basis set cc-pVDZ [62] in cooperation with the core potential MWB-46 [63] for the iodine atoms utilized. A subsequent vibrational analysis was carried out for each fully-relaxed ground state structure to verify that a minimum on the PES was obtained. All equilibrium structures denoted ${ }^{\mathbf{1}} \mathbf{1}^{\mathbf{0}}$ and ${ }^{2} \mathbf{1}^{-1}$, feature merely $C_{2}$ symmetry due to a twist of the phenyl moiety with respect to the central BODIPY core of approximately 85 and $80^{\circ}$, respectively. In order to reduce the computational demand, especially for the subsequent excited state simulations by means of TDDFT and multiconfigurational studies, $\mathrm{C}_{2 \mathrm{v}}$-restricted structures were additionally optimized. These 
structures exhibit two imaginary frequencies, e.g., -84 and $-60 \mathrm{~cm}^{-1}$ for $\mathbf{1}^{\mathbf{1}}$, correlated to the twist of the phenyl-BODIPY carbon-carbon bond.

Excited state properties, such as vertical excitation energies and transition dipole moments, were computed within the adiabatic approximation at the TDDFT level of theory using the same functional and basis set as for the preliminary ground state calculations. For each optimized structure, the 20 lowest excited states of the non-reduced dye (singlet and triplet), as well as for the singly-reduced dye (doublet and quartet), were considered. Furthermore, excited state equilibrium structures were obtained for the states of interest starting from the FC region of the ground state structure. The main focus was set hereby on states displaying photo-induced carbon-iodine bond cleavage, corresponding to the population of at least one $\sigma^{*}$ orbital of the carbon-iodine bonds, and excited states of CT character, implicating an excitation into the phenyl ring from the main $\pi$-system, or vice versa. For the heavy atom mechanism starting from the $S_{0}$ structure, the first three excited singlet states $\left(S_{1}-S_{3}\right)$ were optimized. Moreover, four triplet states of $C T$ character were equilibrated: $T_{6}$ and $T_{11}$ representing an excitation from a phenyl orbital into the LUMO localized at the main $\pi$-system, whereas $T_{12}$ and $T_{13}$ show a transition from the HOMO ( $\pi$-system of boron fragment) to the phenyl fragment. To address carbon-iodine bond breaking, two singlet $\left(\mathrm{S}_{8}\right.$ and $\left.\mathrm{S}_{11}\right)$ and two triplet $\left(\mathrm{T}_{7}\right.$ and $\left.\mathrm{T}_{8}\right)$ states were optimized for mono- and di-dissociation, respectively. The intermediate structures for the chemical reduction mechanism (starting from $\mathrm{D}_{0}$ ) were obtained based on analogous TDDFT simulations and focused on the two low-lying $C T$ states $\left(D_{1}\right.$ and $\left.D_{2}\right)$, as well as on the dissociative states $D_{3}$ and $D_{4}$. In addition, TDDFT simulations within the quartet manifold were performed.

Effects of interaction with a solvent (THF: $\varepsilon=7.4257, n=1.4070$ ) were taken into account for all DFT and TDDFT calculations by the integral equation formalism of the polarizable continuum model [64]. The non-equilibrium procedure of solvation was used for the calculation of excitation energies within the FC region, which is well adapted for processes where only the fast reorganization of the electronic distribution of the solvent is important. In contrast, the equilibrium procedure of solvation was applied for excited state geometry optimizations.

In addition, the computational results obtained by the economical TDDFT simulations were validated against multiconfigurational calculations performed at the RASPT2 $[65,66]$ / /RASSCF $[67,68]$ level of theory. The relativistic ANO-RCC-VDZP basis set [69,70] and the Choleskey decomposition [71] to generate the two-electron integrals were utilized. All calculations were exclusively carried out in the gas phase within the solvated PBE0 ground state geometries $\left({ }^{1} \mathbf{1}^{\mathbf{0}}\right.$ and $\left.{ }^{2} \mathbf{1}^{-\mathbf{1}}\right)$ and with $\mathrm{C}_{2 \mathrm{v}}$ symmetry to reduce the computational costs. To label the restricted active spaces (RASs) utilized in the RASSCF calculations, the notation RAS $(n, l, m ; i, j, k)$ of Gagliardi and co-workers [72] was applied, where $n$ labels the number of active electrons, $l$ the maximum number of holes in the RAS1, $m$ the maximum number of electrons in RAS3, and $i, j$, and $k$ the number of active orbitals in the RAS1, RAS2, and RAS3 subspaces, respectively. The RAS1 consists of orbitals with large occupation numbers, where only a maximum number of electron holes is permitted. Contrary, the RAS3 includes virtual orbitals with occupation numbers close to zero, with only a defined maximum number of electrons being allowed. The RAS2 is equivalent to the active space in the CASSCF method, including all possible electronic configurations.

The aim of the multiconfigurational calculations was to accurately describe the ground state, the first bright state, states leading the carbon-iodine bond breaking, and CT states between the aromatic rings for the non-reduced as well as for the singly reduced dye. Hence, the complete $\pi$-system of the main (heteroaromatic) ring and the $\pi$-system of the attached phenyl ring-excluding the complete bonding and anti-bonding orbitals of both fragments-were incorporated in the active space to ensure a balanced description of the respective states. Furthermore, the p-orbitals of the iodines in plane with the $\pi$-system were included. To describe dissociative processes, two pairs of $\sigma / \sigma^{*}$-orbitals of the C-I bonds were included, leading in consequence to an active space $(24,21)$. Since a complete active space approach would have exceeded the available resources, a RASSCF approaches was chosen, and the 24 orbitals were distributed along the RAS subspaces. Two different RAS partitions, RAS $_{\text {diss }}$ 
and $\mathrm{RAS}_{\mathrm{CT}}$, based on the active space $(24,21)$ were designed (see Figure 5). Each partition enables the description of $S_{0}$ and $D_{0}$, as well as of the bright excited states $S_{1}$ and $D_{5}$ by assigning HOMO-1 $\pi_{2}\left(a_{2}\right)$, $\mathrm{HOMO} \pi_{3}\left(\mathrm{a}_{2}\right)$, and LUMO $\pi_{4}^{*}\left(\mathrm{~b}_{2}\right)$ to RAS2. RAS diss $_{\text {was }}$ wesigned in particular to investigate excited states with dissociative character, i.e., carbon-iodine bond cleavage (non-reduced: $\mathrm{S}_{8}, \mathrm{~S}_{11}, \mathrm{~T}_{7}$, and $\mathrm{T}_{8}$; singly-reduced: $\mathrm{D}_{3}$ and $\left.\mathrm{D}_{4}\right)$. Thus, the two anti-bonding orbitals $\sigma^{*}\left(\mathrm{a}_{1}\right)$ and $\sigma^{*}\left(\mathrm{~b}_{1}\right)$ were assigned

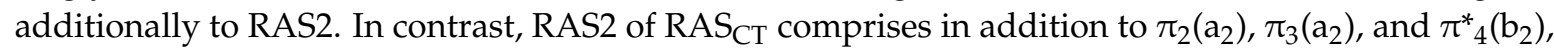
four $\pi$-orbitals of the phenyl moiety, namely $\pi_{\mathrm{ph}, 2}\left(\mathrm{~b}_{1}\right), \pi_{\mathrm{ph}, 3}\left(\mathrm{a}_{2}\right), \pi_{\mathrm{ph}, 4}^{*}\left(\mathrm{a}_{2}\right)$, and $\pi_{\mathrm{ph}, 5}^{*}\left(\mathrm{~b}_{1}\right)$, to investigate CT phenomena among the molecular fragments, i.e., $\mathrm{T}_{6}, \mathrm{~T}_{11}, \mathrm{~T}_{12}$, and $\mathrm{T}_{13}$ of the non-reduced dye and $\mathrm{D}_{1}$ and $\mathrm{D}_{2}$ of the reduced system. Interactions among the subspaces of $\mathrm{RAS}_{\text {diss }}$ and RAS $\mathrm{ST}_{\mathrm{C}}$ were taken into account up to double excitations, which leads in consequence to a $\operatorname{RAS}_{\text {diss }}(21,2,2 ; 10,5,6)$ spanning

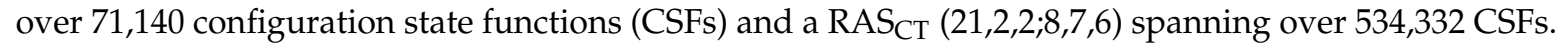

a)

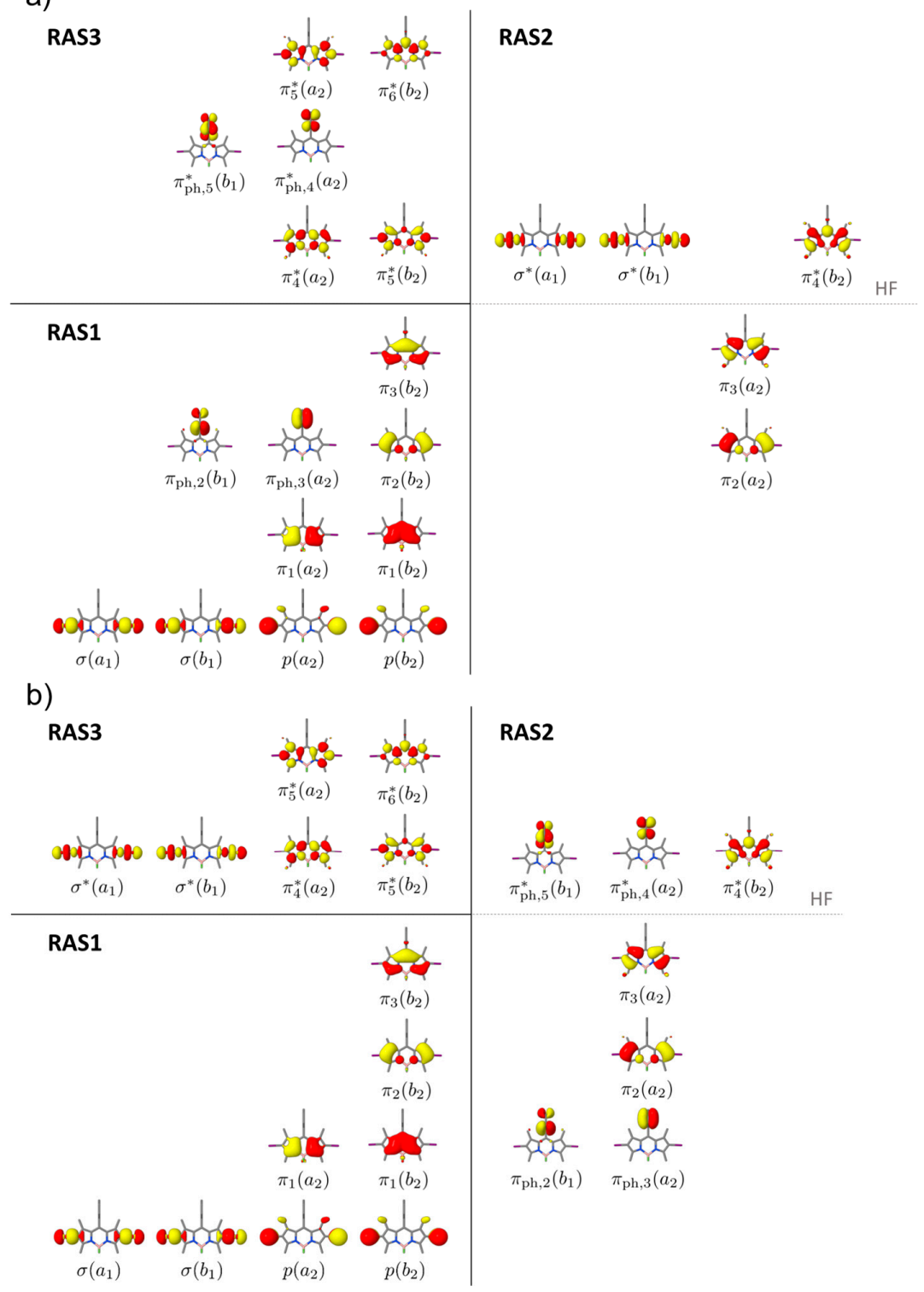

Figure 5. (a) $\operatorname{RAS}_{\text {diss }}(21,2,2 ; 10,5,6)$ and (b) $\operatorname{RAS}_{\mathrm{CT}}(21,2,2 ; 8,7,6)$ to describe ground, bright, and dissociative or CT-excited states for both mechanisms within their $\mathrm{C}_{2 \mathrm{v}}$ optimized ground state (PBE0/cc-pvdz) structure $\left({ }^{\mathbf{1}} \mathbf{1}^{\mathbf{0}}\right.$ and $\left.\mathbf{2}^{\mathbf{2}} \mathbf{1}^{\mathbf{1}}\right)$. The distribution over the subspaces RAS1, RAS2, and RAS3 is displayed, the occupation within the Hartree-Fock (HF) reference wave function is indicated by the gray dashed line. 
State-average (SA-)RASSCF calculations including the first four roots in each spatial symmetry and multiplicity were carried out using both RASs in the ${ }^{\mathbf{1}} \mathbf{1}^{\mathbf{0}}$ and ${ }^{\mathbf{2}} \mathbf{1}^{\mathbf{- 1}}$ geometry. Dynamical correlation was added my means of multistate (MS-)RASPT2 [73] on the SA-RASSCF reference wave functions, while the core electrons were kept frozen and a real level shift [74] of 0.3 a.u. was applied to prevent intruder states.

Transition dipole moments and SOCs-between singlet and triplet states-were obtained at the RASSCF and RASPT2 levels of theory using the CAS state interaction method [75]. The SOCs rest on an effective one-electron spin-orbit Hamiltonian and atomic mean field integrals [76]. They were obtained between the bright and the dissociative states (utilizing RAS $_{\text {diss }}$ ), as well as between the bright and the $\mathrm{CT}$ states (utilizing $\mathrm{RAS}_{\mathrm{CT}}$ ) in ${ }^{\mathbf{1}} \mathbf{1}^{\mathbf{0}}$, and along selected coordinates, i.e., linear-interpolated Cartesian coordinates (LICCs), vibrational normal modes, as well as relaxed scans along bond lengths and dihedral angles. The carbon-iodine dissociation was studied along a symmetric and an antisymmetric elongation of both respective bonds. In case of the CT processes, a dihedral angle describing the torsion of the two aromatic systems was utilized. The excited state potential energy landscape along these coordinates was assessed exclusively by virtue of TDDFT. The symmetric bond cleavage $\left(\mathrm{A}_{1}\right.$ displacement, non-relaxed coordinate) was, furthermore, investigated at the RASPT2 level of theory including SOCs, while the first two roots in each spatial symmetry and multiplicity were calculated. This coordinate was intentionally chosen to allow the application of multiconfigurational methods.

In addition, the rate constant for a population transfer from the bright $S_{1}$ state towards the triplet manifold upon photoexcitation was assessed for the non-reduced dye. Therefore, the golden-rule expression for radiationless transitions was adapted for ISC rate constants and SOCs as interacting perturbation-potential. These rate constants, $k_{\mathrm{ISC}}$, were obtained along LICCs connecting the FC region with the equilibrated $\mathrm{T}_{7}$ and $\mathrm{T}_{8}$ structures, respectively, by [58]:

$$
k_{\mathrm{ISC}}^{i f}=\frac{2 \pi}{h}\left|\left\langle\Psi_{i}\left|\hat{H}_{\mathrm{SOC}}\right| \Psi_{f}\right\rangle\right|^{2} \frac{1}{\sqrt{4 \pi \lambda R T}} \exp \left[-\frac{(\Delta E+\lambda)^{2}}{4 \lambda R T}\right]
$$

Here, $\Delta E$ is the energy difference between the optimized states, $\lambda$ the reorganization energy and $\left\langle\Psi_{i}\left|\hat{H}_{\mathrm{SOC}}\right| \Psi_{f}\right\rangle$ the SOC matrix element between the initial state $i$ and the final state $f$. The ground and excited state geometries and excited state energies were obtained by DFT and TDDFT, while SOCs were rationalized by RASPT2 calculations within the FC region. Equation (1) was evaluated at room temperature $(298 \mathrm{~K})$.

\section{Conclusions}

The aim of the present computational study was to elucidate the photophysical and photochemical processes leading to the formation of the catalytically active species of a BODIPY-based photosensitizer in the scope of light-driven hydrogen evolution, as well as to identify prominent excited-state relaxation channels associated to the photodegradation of the dye. The preliminarily performed benchmark of the excited states properties obtained by economical TDDFT calculations against state-of-the-art multiconfigurational simulations, namely MS-RASPT2, showed that the PBE0 functional is able to estimate the potential energy landscape in the ground state structure of the non-reduced and the singly reduced photosensitizer in reasonable agreement with MS-RASPT2. The formation of the catalytically active charge-separated species was investigated by virtue of two postulated mechanisms: (i) The first mechanism relies on the initial photo-excitation of the non-reduced species and a subsequent ultrafast population transfer to low-lying charge-separated triplet states based on the SOCs introduced by the iodine atoms attached to the BODIPY core; (ii) The preliminary step in the second mechanism is a chemical reduction of the PS by the sacrificial electron donor (triethylamine) and a subsequent photo-induced charge transfer. Within (i), the crucial step involves an ISC from the bright excited singlet state towards the triplet manifold. The potential energy landscape as well as the minor SOCs obtained by MS-RASPT2 and TDDFT suggest that the population of long-lived charge-separated triplet 
states is highly unlikely, see Scheme 2a. However, the quantum chemical calculations performed for the singly-reduced dye reveal a pronounced stabilization of CT states between the BODIPY moiety and the attached phenyl group, which are further lowered upon partial excited-state planarization of the two aromatic fragments. Therefore, the formation of the catalytically active species is found to be related to the reduction of the BODIPY photosensitizer prior to the photoexcitation, see Scheme $2 \mathrm{~b}$.

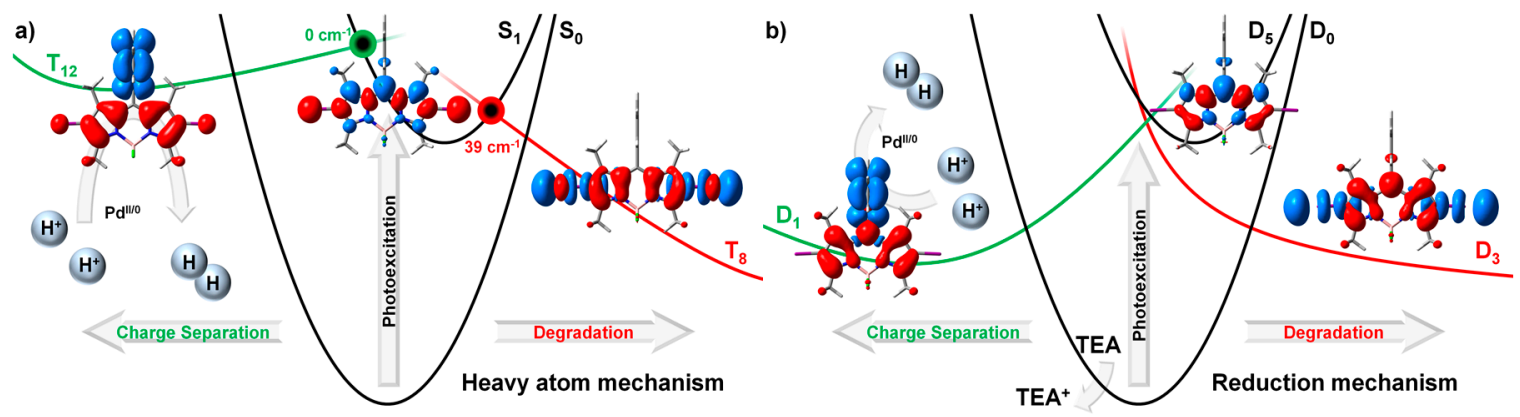

Scheme 2. Excited-states processes associated to photo-induced charge separation (green) and degradation (red) for, (a) the heavy atom mechanism and, (b) the reduction mechanism.

Furthermore, the photodegradation processes, i.e., the dissociation of iodine, were identified for the non-reduced as well as for the singly-reduced species. Cleavage of the carbon-iodine bond(s) within the excited singlet states of the non-reduced dye is energetically unfavorable, while SOCs of up to $\sim 50 \mathrm{~cm}^{-1}$ may lead to an ISC towards the energetically less unfavorable dissociative triplet states on longer time scales. In contrast, the light-driven cleavage of the carbon-iodine bond(s) was found to be a prominent excited-state relaxation channel of the singly-reduced dye.

Thus, this study does not support to ascribe the enhanced catalytic performance of the present BODIPY dye with respect to its unsubstituted parent species to a heavy atom effect introduced by the iodine atoms. Further quantum chemical and quantum dynamical investigations are envisaged for the parent dye in order to rationalize the impact of iodine substitution (2,6 position) with respect to the photophysical and photochemical properties as well as for dyes incorporating electron donating substituents at the 2,6 position, e.g., methoxy groups, that allow to stabilize the desired charge-separated intermediates and to enhance the photostability simultaneously.

Supplementary Materials: The following are available online at http:/ /www.mdpi.com/2073-4344/8/11/520/s1, Details and additional information regarding the preliminary MS-RASPT2/TDDFT benchmark, TDDFT results for singlet and triplet states $\left(\mathbf{1}^{\mathbf{0}}\right)$ and doublet states $\left({ }^{\mathbf{2}} \mathbf{1}^{-\mathbf{1}}\right)$, selected vibrational normal modes, SOCs and rate constants, as well as PESs along selected coordinates.

Author Contributions: K.M.Z. performed all quantum chemical simulation; S.K. and S.G. supervised the present study; K.M.Z. and S.K. analyzed the data; and K.M.Z., S.G., and S.K. wrote the paper.

Funding: This research received no external funding.

Acknowledgments: K.M.Z. gratefully acknowledges generous support from the Konrad Adenauer foundation and the German Academic Scholarship Foundation. S.K. and S.G. thank the Thuringian State Government for financial support within the ACP Explore project. The authors thank Torsten Beweries for fruitful discussions. All calculations were performed at the Universitätsrechenzentrum of the Friedrich-Schiller University of Jena.

Conflicts of Interest: The authors declare no conflict of interest.

\section{References}

1. Lewis, N.S.; Nocera, D.G. Powering the planet: Chemical challenges in solar energy utilization. Proc. Natl. Acad. Sci. USA 2006, 103, 15729-15735. [CrossRef] [PubMed]

2. Kim, D.; Sakimoto, K.K.; Hong, D.; Yang, P. Artificial photosynthesis for sustainable fuel and chemical production. Angew. Chem. Int. Ed. 2015, 54, 3259-3266. [CrossRef] [PubMed]

3. Esswein, A.J.; Nocera, D.G. Hydrogen production by molecular photocatalysis. Chem. Rev. 2007, 107, 4022-4047. [CrossRef] [PubMed] 
4. Chu, S.; Majumdar, A. Opportunities and challenges for a sustainable energy future. Nature 2012, 488, 294-303. [CrossRef] [PubMed]

5. Yuan, Y.-J.; Yu, Z.-T.; Chen, D.-Q.; Zou, Z.-G. Metal-complex chromophores for solar hydrogen generation. Chem. Soc. Rev. 2017, 46, 603-631. [CrossRef] [PubMed]

6. Liao, W.-M.; Zhang, J.-H.; Hou, Y.-J.; Wang, H.-P.; Pan, M. Visible-light-driven $\mathrm{CO}_{2}$ photo-catalytic reduction of $\mathrm{Ru}(\mathrm{II})$ and $\mathrm{Ir}(\mathrm{III})$ coordination complexes. Inorg. Chem. Commun. 2016, 73, 80-89. [CrossRef]

7. Barber, J. Photosynthetic energy conversion: Natural and artificial. Chem. Soc. Rev. 2009, 38, $185-196$. [CrossRef] [PubMed]

8. Wang, X.; Maeda, K.; Chen, X.; Takanabe, K.; Domen, K.; Hou, Y.; Fu, X.; Antonietti, M. Polymer semiconductors for artificial photosynthesis: Hydrogen evolution by mesoporous graphitic carbon nitride with visible light. J. Am. Chem. Soc. 2009, 131, 1680-1681. [CrossRef] [PubMed]

9. Zhang, P.; Zhang, J.; Gong, J. Tantalum-based semiconductors for solar water splitting. Chem. Soc. Rev. 2014, 43, 4395-4422. [CrossRef] [PubMed]

10. Yang, J.; Wang, D.; Han, H.; Li, C. Roles of cocatalysts in photocatalysis and photoelectrocatalysis. Acc. Chem. Res. 2013, 46, 1900-1909. [CrossRef] [PubMed]

11. Chang, K.; Mei, Z.; Wang, T.; Kang, Q.; Ouyang, S.; Ye, J. MoS 2 /graphene cocatalyst for efficient photocatalytic $\mathrm{H}_{2}$ evolution under visible light irradiation. ACS Nano 2014, 8, 7078-7087. [CrossRef] [PubMed]

12. Wu, B.; Liu, D.; Mubeen, S.; Chuong, T.T.; Moskovits, M.; Stucky, G.D. Anisotropic growth of $\mathrm{TiO}_{2}$ onto gold nanorods for plasmon-enhanced hydrogen production from water reduction. J. Am. Chem. Soc. 2016, 138, 1114-1117. [CrossRef] [PubMed]

13. Zhang, X.; Jin, Z.; Li, Y.; Li, S.; Lu, G. Efficient Photocatalytic Hydrogen Evolution from Water without an Electron Mediator over Pt-Rose Bengal Catalysts. J. Phys. Chem. C 2009, 113, 2630-2635. [CrossRef]

14. Gong, L.; Wang, J.; Li, H.; Wang, L.; Zhao, J.; Zhu, Z. Acriflavine-cobaloxime-triethanolamine homogeneous photocatalytic system for water splitting and the multiple effects of cobaloxime and triethanolamine. Catal. Commun. 2011, 12, 1099-1103. [CrossRef]

15. Zhang, W.; Hong, J.; Zheng, J.; Huang, Z.; Zhou, J.; Xu, R. Nickel-thiolate complex catalyst assembled in one step in water for solar $\mathrm{H}_{2}$ production. J. Am. Chem. Soc. 2011, 133, 20680-20683. [CrossRef] [PubMed]

16. Lazarides, T.; McCormick, T.; Du, P.; Luo, G.; Lindley, B.; Eisenberg, R. Making hydrogen from water using a homogeneous system without noble metals. J. Am. Chem. Soc. 2009, 131, 9192-9194. [CrossRef] [PubMed]

17. McCormick, T.M.; Calitree, B.D.; Orchard, A.; Kraut, N.D.; Bright, F.V.; Detty, M.R.; Eisenberg, R. Reductive side of water splitting in artificial photosynthesis: New homogeneous photosystems of great activity and mechanistic insight. J. Am. Chem. Soc. 2010, 132, 15480-15483. [CrossRef] [PubMed]

18. Chen, N.-Y.; Xia, L.-M.; Lennox, A.J.; Sun, Y.-Y.; Chen, H.; Jin, H.-M.; Junge, H.; Wu, Q.-A.; Jia, J.-H.; Beller, M.; et al. Structure-Activated Copper Photosensitisers for Photocatalytic Water Reduction. Chem. Eur. J. 2017, 23, 3631-3636. [CrossRef] [PubMed]

19. Rau, S.; Schäfer, B.; Gleich, D.; Anders, E.; Rudolph, M.; Friedrich, M.; Görls, H.; Henry, W.; Vos, J.G. Ein supramolekularer Photokatalysator zur Erzeugung von Wasserstoff und zur selektiven Hydrierung von Tolan. Angew. Chem. 2006, 118, 6361-6364. [CrossRef]

20. Kirch, M.; Lehn, J.-M.; Sauvage, J.-P. Hydrogen generation by visible light irradiation of aqueous solutions of metal complexes. An approach to the photochemical conversion and storage of solar energy. Helv. Chim. Acta 1979, 62, 1345-1384. [CrossRef]

21. Du, P.; Knowles, K.; Eisenberg, R. A homogeneous system for the photogeneration of hydrogen from water based on a platinum(II) terpyridyl acetylide chromophore and a molecular cobalt catalyst. J. Am. Chem. Soc. 2008, 130, 12576-12577. [CrossRef] [PubMed]

22. Metz, S.; Bernhard, S. Robust photocatalytic water reduction with cyclometalated Ir(III) 4-vinyl-2,2'bipyridine complexes. Chem. Commun. 2010, 46, 7551-7553. [CrossRef] [PubMed]

23. DiSalle, B.F.; Bernhard, S. Orchestrated photocatalytic water reduction using surface-adsorbing iridium photosensitizers. J. Am. Chem. Soc. 2011, 133, 11819-11821. [CrossRef] [PubMed]

24. Whang, D.R.; Sakai, K.; Park, S.Y. Highly efficient photocatalytic water reduction with robust iridium(III) photosensitizers containing arylsilyl substituents. Angew. Chem. Int. Ed. 2013, 52, 11612-11615. [CrossRef] [PubMed] 
25. Mak, C.S.; Wong, H.L.; Leung, Q.Y.; Tam, W.Y.; Chan, W.K.; Djurišić, A.B. The use of sublimable chlorotricarbonyl bis(phenylimino) acenaphthene rhenium(I) complexes as photosensitizers in bulk-heterojunction photovoltaic devices. J. Organomet. Chem. 2009, 694, 2770-2776. [CrossRef]

26. Eckenhoff, W.T.; Eisenberg, R. Molecular systems for light driven hydrogen production. Dalton Trans. 2012, 41, 13004-13021. [CrossRef] [PubMed]

27. Cossi, M.; Rega, N.; Scalmani, G.; Barone, V. Energies, structures, and electronic properties of molecules in solution with the C-PCM solvation model. J. Comput. Chem. 2003, 24, 669-681. [CrossRef] [PubMed]

28. Lakadamyali, F.; Kato, M.; Muresan, N.M.; Reisner, E. Selective reduction of aqueous protons to hydrogen with a synthetic cobaloxime catalyst in the presence of atmospheric oxygen. Angew. Chem. Int. Ed. 2012, 51, 9381-9384. [CrossRef] [PubMed]

29. Sakai, T.; Mersch, D.; Reisner, E. Photocatalytic Hydrogen Evolution with a Hydrogenase in a Mediator-Free System under High Levels of Oxygen. Angew. Chem. Int. Ed. 2013, 52, 12313-12316. [CrossRef] [PubMed]

30. Cheng, M.; Yang, X.; Li, J.; Zhang, F.; Sun, L. Co-sensitization of Organic Dyes for Efficient Dye-Sensitized Solar Cells. ChemSusChem 2013, 6, 70-77. [CrossRef] [PubMed]

31. Zhang, P.; Wang, M.; Li, C.; Li, X.; Dong, J.; Sun, L. Photochemical $\mathrm{H}_{2}$ production with noble-metal-free molecular devices comprising a porphyrin photosensitizer and a cobaloxime catalyst. Chem. Commun. 2010, 46, 8806-8808. [CrossRef] [PubMed]

32. Han, Z.; McNamara, W.R.; Eum, M.-S.; Holland, P.L.; Eisenberg, R. A Nickel Thiolate Catalyst for the Long-Lived Photocatalytic Production of Hydrogen in a Noble-Metal-Free System. Angew. Chem. Int. Ed. 2012, 51, 1667-1670. [CrossRef] [PubMed]

33. Hartley, C.L.; DiRisio, R.J.; Screen, M.E.; Mayer, K.J.; McNamara, W.R. Iron polypyridyl complexes for photocatalytic hydrogen generation. Inorg. Chem. 2016, 55, 8865-8870. [CrossRef] [PubMed]

34. Sabatini, R.P.; McCormick, T.M.; Lazarides, T.; Wilson, K.C.; Eisenberg, R.; McCamant, D.W. Intersystem crossing in halogenated Bodipy chromophores used for solar hydrogen production. J. Phys. Chem. Lett. 2011, 2, 223-227. [CrossRef]

35. Bartelmess, J.; Francis, A.J.; El Roz, K.A.; Castellano, F.N.; Weare, W.W.; Sommer, R.D. Light-driven hydrogen evolution by bodipy-sensitized cobaloxime catalysts. Inorg. Chem. 2014, 53, 4527-4534. [CrossRef] [PubMed]

36. Manton, J.C.; Long, C.; Vos, J.G.; Pryce, M.T. A photo-and electrochemical investigation of BODIPY-cobaloxime complexes for hydrogen production, coupled with quantum chemical calculations. Phys. Chem. Chem. Phys. 2014, 16, 5229-5236. [CrossRef] [PubMed]

37. Luo, G.-G.; Fang, K.; Wu, J.-H.; Dai, J.-C.; Zhao, Q.-H. Noble-metal-free BODIPY-cobaloxime photocatalysts for visible-light-driven hydrogen production. Phys. Chem. Chem. Phys. 2014, 16, 23884-23894. [CrossRef] [PubMed]

38. Luo, G.-G.; Fang, K.; Wu, J.-H.; Mo, J. Photocatalytic water reduction from a noble-metal-free molecular dyad based on a thienyl-expanded BODIPY photosensitizer. Chem. Commun. 2015, 51, 12361-12364. [CrossRef] [PubMed]

39. Luo, G.-G.; Lu, H.; Zhang, X.-L.; Dai, J.-C.; Wu, J.-H.; Wu, J.-J. The relationship between the boron dipyrromethene (BODIPY) structure and the effectiveness of homogeneous and heterogeneous solar hydrogen-generating systems as well as DSSCs. Phys. Chem. Chem. Phys. 2015, 17, 9716-9729. [CrossRef] [PubMed]

40. Loudet, A.; Burgess, K. BODIPY dyes and their derivatives: Syntheses and spectroscopic properties. Chem. Rev. 2007, 107, 4891-4932. [CrossRef] [PubMed]

41. Ulrich, G.; Ziessel, R.; Harriman, A. The chemistry of fluorescent bodipy dyes: Versatility unsurpassed. Angew. Chem. Int. Ed. 2008, 47, 1184-1201. [CrossRef] [PubMed]

42. Momeni, M.R.; Brown, A. Why do TD-DFT excitation energies of BODIPY/aza-BODIPY families largely deviate from experiment? Answers from electron correlated and multireference methods. J. Chem. Theory Comput. 2015, 11, 2619-2632. [CrossRef] [PubMed]

43. Ni, Y.; Zeng, W.; Huang, K.-W.; Wu, J. Benzene-fused BODIPYs: Synthesis and the impact of fusion mode. Chem. Commun. 2013, 49, 1217-1219. [CrossRef] [PubMed]

44. Gresser, R.; Hartmann, H.; Wrackmeyer, M.; Leo, K.; Riede, M. Synthesis of thiophene-substituted aza-BODIPYs and their optical and electrochemical properties. Tetrahedron 2011, 67, 7148-7155. [CrossRef] 
45. Hayashi, Y.; Obata, N.; Tamaru, M.; Yamaguchi, S.; Matsuo, Y.; Saeki, A.; Seki, S.; Kureishi, Y.; Saito, S.; Yamaguchi, S.; et al. Facile synthesis of biphenyl-fused BODIPY and its property. Org. Lett. 2012, 14, 866-869. [CrossRef] [PubMed]

46. Jiang, X.-D.; Fu, Y.; Zhang, T.; Zhao, W. Synthesis and properties of NIR aza-BODIPYs with aryl and alkynyl substituents on the boron center. Tetrahedron Lett. 2012, 53, 5703-5706. [CrossRef]

47. Yu, C.; Xu, Y.; Jiao, L.; Zhou, J.; Wang, Z.; Hao, E. Isoindole-BODIPY Dyes as Red to Near-Infrared Fluorophores. Chem. Eur. J. 2012, 18, 6437-6442. [CrossRef] [PubMed]

48. Berhe, S.A.; Rodriguez, M.T.; Park, E.; Nesterov, V.N.; Pan, H.; Youngblood, W.J. Optoelectronic Tuning of Organoborylazadipyrromethenes via Effective Electronegativity at the Metalloid Center. Inorg. Chem. 2014, 53, 2346-2348. [CrossRef] [PubMed]

49. Sarkar, S.K.; Mukherjee, S.; Thilagar, P. Going beyond red with a tri-and tetracoordinate boron conjugate: Intriguing near-IR optical properties and applications in anion sensing. Inorg. Chem. 2014, 53, $2343-2345$. [CrossRef] [PubMed]

50. Dura, L.; Wächtler, M.; Kupfer, S.; Kübel, J.; Ahrens, J.; Höfler, S.; Bröring, M.; Dietzek, B.; Beweries, T. Photophysics of BODIPY Dyes as Readily-Designable Photosensitisers in Light-Driven Proton Reduction. Inorganics 2017, 5, 21. [CrossRef]

51. Dura, L.; Ahrens, J.; Pohl, M.-M.; Höfler, S.; Bröring, M.; Beweries, T. Design of BODIPY Dyes as Photosensitisers in Multicomponent Catalyst Systems for Light-Driven Hydrogen Production. Chem. Eur. J. 2015, 21, 13549-13552. [CrossRef] [PubMed]

52. Staniszewska, M.; Kupfer, S.; Łabuda, M.; Guthmuller, J. Theoretical Assessment of Excited State Gradients and Resonance Raman Intensities for the Azobenzene Molecule. J. Chem. Theory Comput. 2017, 13, 1263-1274. [CrossRef] [PubMed]

53. Caricato, M.; Lipparini, F.; Scalmani, G.; Cappelli, C.; Barone, V. Vertical Electronic Excitations in Solution with the EOM-CCSD Method Combined with a Polarizable Explicit/Implicit Solvent Model. J. Chem. Theory Comput. 2013, 9, 3035-3042. [CrossRef] [PubMed]

54. Kállay, M.; Gauss, J. Calculation of excited-state properties using general coupled-cluster and configuration-interaction models. J. Chem. Phys. 2004, 121, 9257-9269. [CrossRef] [PubMed]

55. Spiegel, J.D.; Kleinschmidt, M.; Larbig, A.; Tatchen, J.; Marian, C.M. Quantum-Chemical Studies on Excitation Energy Transfer Processes in BODIPY-Based Donor-Acceptor Systems. J. Chem. Theory Comput. 2015, 11, 4316-4327. [CrossRef] [PubMed]

56. Chibani, S.; Laurent, A.D.; Le Guennic, B.; Jacquemin, D. Improving the Accuracy of Excited-State Simulations of BODIPY and Aza-BODIPY Dyes with a Joint SOS-CIS(D) and TD-DFT Approach. J. Chem. Theory Comput. 2014, 10, 4574-4582. [CrossRef] [PubMed]

57. Ji, S.; Ge, J.; Escudero, D.; Wang, Z.; Zhao, J.; Jacquemin, D. Molecular Structure-Intersystem Crossing Relationship of Heavy-Atom-Free BODIPY Triplet Photosensitizers. J. Org. Chem. 2015, 80, 5958-5963. [CrossRef] [PubMed]

58. Escudero, D.; Happ, B.; Winter, A.; Hager, M.D.; Schubert, U.S.; González, L. The Radiative Decay Rates Tune the Emissive Properties of Ruthenium(II) Polypyridyl Complexes: A Computational Study. Chem. Asian J. 2012, 7, 667-671. [CrossRef] [PubMed]

59. Frisch, M.; Trucks, G.; Schlegel, H.B.; Scuseria, G.; Robb, M.; Cheeseman, J.; Scalmani, G.; Barone, V.; Mennucci, B.; Petersson, G.; et al. Gaussian 09; Revision A. 02; Gaussian Inc.: Wallingford, CT, USA, 2009.

60. Aquilante, F.; Autschbach, J.; Carlson, R.K.; Chibotaru, L.F.; Delcey, M.G.; De Vico, L.; Ferré, N.; Frutos, L.M.; Gagliardi, L.; Garavelli, M.; et al. Molcas 8: New capabilities for multiconfigurational quantum chemical calculations across the periodic table. J. Comput. Chem. 2016, 37, 506-541. [CrossRef] [PubMed]

61. Adamo, C.; Barone, V. Toward reliable density functional methods without adjustable parameters: The PBE0 model. J. Chem. Phys. 1999, 110, 6158-6170. [CrossRef]

62. Godbout, N.; Salahub, D.R.; Andzelm, J.; Wimmer, E. Optimization of Gaussian-type basis sets for local spin density functional calculations. Part I. Boron through neon, optimization technique and validation. Can. J. Chem. 1992, 70, 560-571. [CrossRef]

63. Figgen, D.; Rauhut, G.; Dolg, M.; Stoll, H. Energy-consistent pseudopotentials for group 11 and 12 atoms: Adjustment to multi-configuration Dirac-Hartree-Fock data. Chem. Phys. 2005, 311, 227-244. [CrossRef] 
64. Mennucci, B.; Tomasi, J.; Cammi, R.; Cheeseman, J.; Frisch, M.; Devlin, F.; Gabriel, S.; Stephens, P. Polarizable continuum model (PCM) calculations of solvent effects on optical rotations of chiral molecules. J. Phys. Chem. A 2002, 106, 6102-6113. [CrossRef]

65. Malmqvist, P.-Å.; Pierloot, K.; Shahi, A.R.M.; Cramer, C.J.; Gagliardi, L. The restricted active space followed by second-order perturbation theory method: Theory and application to the study of $\mathrm{CuO}_{2}$ and $\mathrm{Cu}_{2} \mathrm{O}_{2}$ systems. J. Chem. Phys. 2008, 128, 204109. [CrossRef] [PubMed]

66. Li Manni, G.; Aquilante, F.; Gagliardi, L. Strong correlation treated via effective hamiltonians and perturbation theory. J. Chem. Phys. 2011, 134, 034114. [CrossRef] [PubMed]

67. Malmqvist, P.-Å.; Rendell, A.; Roos, B.O. The restricted active space self-consistent-field method, implemented with a split graph unitary group approach. J. Phys. Chem. 1990, 94, 5477-5482. [CrossRef]

68. Olsen, J.; Roos, B.O.; Jorgensen, P.; Jensen, H.J.A. Determinant based configuration interaction algorithms for complete and restricted configuration interaction spaces. J. Chem. Phys. 1988, 89, 2185-2192. [CrossRef]

69. Pierloot, K.; Dumez, B.; Widmark, P.-O.; Roos, B.O. Density matrix averaged atomic natural orbital (ANO) basis sets for correlated molecular wave functions. Theor. Chim. Acta 1995, 90, 87-114. [CrossRef]

70. Roos, B.O.; Lindh, R.; Malmqvist, P.-Å.; Veryazov, V.; Widmark, P.-O. New relativistic ANO basis sets for transition metal atoms. J. Phys. Chem. A 2005, 109, 6575-6579. [CrossRef] [PubMed]

71. Aquilante, F.; Lindh, R.; Bondo Pedersen, T. Unbiased auxiliary basis sets for accurate two-electron integral approximations. J. Chem. Phys. 2007, 127, 114107. [CrossRef] [PubMed]

72. Sauri, V.; Serrano-Andrés, L.; Shahi, A.R.M.; Gagliardi, L.; Vancoillie, S.; Pierloot, K. Multiconfigurational Second-Order Perturbation Theory Restricted Active Space (RASPT2) Method for Electronic Excited States: A Benchmark Study. J. Chem. Theory Comput. 2011, 7, 153-168. [CrossRef] [PubMed]

73. Finley, J.; Malmqvist, P.-Å.; Roos, B.O.; Serrano-Andrés, L. The multi-state CASPT2 method. Chem. Phys. Lett. 1998, 288, 299-306. [CrossRef]

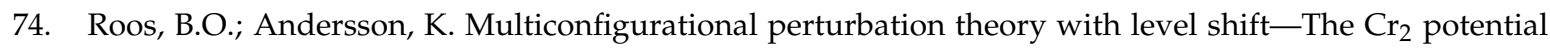
revisited. Chem. Phys. Lett. 1995, 245, 215-223. [CrossRef]

75. Malmqvist, P.-Å.; Roos, B.O. The CASSCF state interaction method. Chem. Phys. Lett. 1989, 155, $189-194$. [CrossRef]

76. Malmqvist, P.-Å.; Roos, B.O.; Schimmelpfennig, B. The restricted active space (RAS) state interaction approach with spin-orbit coupling. Chem. Phys. Lett. 2002, 357, 230-240. [CrossRef] 